\title{
The indications and timing for operative management of spinal epidural abscess: literature review and treatment algorithm
}

\author{
Alexander Tuchman, M.D., Martin Pham, M.D., and Patrick C. Hsieh, M.D. \\ Department of Neurosurgery, Keck School of Medicine, Los Angeles County-University of Southern \\ California Medical Center, Los Angeles, California
}

\begin{abstract}
Object. Delayed or inappropriate treatment of spinal epidural abscess (SEA) can lead to serious morbidity or death. It is a rare event with significant variation in its causes, anatomical locations, and rate of progression. Traditionally the treatment of choice has involved emergency surgical evacuation and a prolonged course of antibiotics tailored to the offending pathogen. Recent publications have advocated antibiotic treatment without surgical decompression in select patient populations. Clearly defining those patients who can be safely treated in this manner remains in evolution. The authors review the current literature concerning the treatment and outcome of SEA to make recommendations concerning what population can be safely triaged to nonoperative management and the optimal timing of surgery.

Methods. A PubMed database search was performed using a combination of search terms and Medical Subject Headings, to identify clinical studies reporting on the treatment and outcome of SEA.

Results. The literature review revealed 28 original case series containing at least 30 patients and reporting on treatment and outcome. All cohorts were deemed Class III evidence, and in all but two the data were obtained retrospectively. Based on the conclusions of these studies along with selected smaller studies and review articles, the authors present an evidence-based algorithm for selecting patients who may be safe candidates for nonoperative management.

Conclusions. Patients who are unable to undergo an operation, have a complete spinal cord injury more than 48 hours with low clinical or radiographic concern for an ascending lesion, or who are neurologically stable and lack risk factors for failure of medical management may be initially treated with antibiotics alone and close clinical monitoring. If initial medical management is to be undertaken the patient should be made aware that delayed neurological deterioration may not fully resolve even after prompt surgical treatment. Patients deemed good surgical candidates should receive their operation as soon as possible because the rate of clinical deterioration with SEA is notoriously unpredictable. Although patients tend to recover from neurological deficits after treatment of SEA, the time point when a neurological injury becomes irreversible is unknown, supporting emergency surgery in those patients with acute findings.
\end{abstract}

(http://thejns.org/doi/abs/10.3171/2014.6.FOCUS14261)

\section{Key Words •}

$\mathrm{S}$ PINAL epidural abscess (SEA) was initially described by Morgagni in $1761 .{ }^{46}$ Subsequently, the surgical treatment of SEA was reported by Barth in 1901, but it remained a generally fatal disease process until diagnostic advances allowed for early surgical decompression to couple with antibiotics. ${ }^{9,27,45,51,63}$ In 1948 Heusner ${ }^{27}$ published his landmark case series and review of the literature in which the classic disease progression through spinal ache (phase I), root pain (phase II), weak-

\footnotetext{
Abbreviations used in this paper: CRP = C-reactive protein; MRSA = methicillin-resistant Staphylococcus aureus; SEA = spinal epidural abscess; $\mathrm{WBC}=$ white blood cell.
}

ness (phase III), and paralysis (phase IV) was first described. The thesis of this paper and the majority of publications to follow was that early diagnosis and treatment

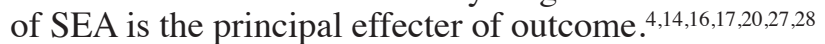

Spinal epidural abscess is a rare diagnosis with an incidence of approximately $0.2-2$ cases per 10,000 admissions. . $^{4,17,28,47,51}$ Meanwhile low-back pain affects approximately $80 \%$ of the US population at some point in their life. ${ }^{26}$ This disparity highlights why the primary hurdle in effectively treating SEA is at the diagnostic stage. Delay in diagnosis is reported in as high as $75 \%-89 \%$ of patients with SEA, probably because very few present with the "classic triad" of fever, spine pain, and neurological defi- 
cit. ${ }^{20,62}$ Sensitivity for SEA can be improved by screening patients for risk factors such as diabetes, intravenous drug use, alcohol abuse, other sites of infection, trauma, history of invasive procedures, or immunosuppression. ${ }^{19,51}$ Laboratory tests such as C-reactive protein (CRP), erythrocyte sedimentation rate, and complete blood count can help triage those patients who are highest risk. ${ }^{17,20,51}$ These steps, along with improvements in both the quality and availability of MRI, allow patients to be diagnosed and treated earlier in the disease process, driving mortality rates down to around $5 \%$ in modern series. ${ }^{17}$

This condition is defined by a pyogenic infection of the potential space between the vertebral body and dura mater of the spine. ${ }^{23,51,58}$ The epidural space can be seeded with infection by a variety of mechanisms including hematogenous spread $(50 \%)$, direct extension from adjacent infection (33\%), inoculation from spinal procedures (15\%), or unknown mechanisms. ${ }^{17,53,57}$ Although Staphylococcus aureus causes approximately two-thirds of spinal abscesses, other infecting pathogens including gram-positive and -negative bacteria, anaerobic bacteria, mycobacteria, fungi, and parasites have also been implicated. ${ }^{33,35,51,54}$

The pathogenesis by which infection in the epidural space leads to neurological deficit remains a controversial topic, with evidence for both direct compression and vascular occlusion caused by septic thrombophlebitis as the offending mechanism. . $23,24,30,55,66$ The direct-inoculation rabbit model studied by Feldenzer et al. along with the clinical improvement seen after surgically addressing mass effect caused by SEA, support the direct compression model..$^{13,23,24}$ However, instances of rapid clinical deterioration in the absence of radiographic compression and postmortem examinations showing venous and arterial thrombosis lend credence to a vascular etiology. $8,30,55,66$ Probably both factors potentiate the development of neurological injury and help explain why the clinical course is often unpredictable. ${ }^{58}$

The treatment of SEA is two-pronged, with antibiotics for treating the systemic manifestations and surgery for local disease control. When surgery is required a posterior laminectomy is the most common approach. ${ }^{51}$ In cases of isolated ventral compression an anterior or lateral approach, often coupled with corpectomy, may be required. ${ }^{36,41}$ Less invasive methods of surgical evacuation such as CT-guided needle aspiration, hemilaminectomy, and interlaminar fenestration have been reported, with promising results. ${ }^{5,15,16,42,54,59}$ When presented with extensive SEA, the options to avoid a multilevel laminectomy include suction irrigation catheters passed through endor intermediate-level laminectomies or multilevel unilateral fenestrations. ${ }^{39,49}$

Over the 250 years since SEA was first described, our knowledge base, diagnostic tools, and treatments have improved significantly. However, SEA remains a rare event with significant variation in its causes, anatomical locations, and rate of progression. This makes it difficult to build a strong evidence base stratifying patients to the most effective treatment algorithm. In fact the medical literature includes only 28 case series, containing at least 30 subjects, and reporting on the treatment and outcome of SEA. . $3,4,6,11-14,16,18-20,28,31,32,34,36,37,47,48,54,56,59,61,62,65,69,72_{\text {This }}$ paucity of good clinical data hampers our ability to make definitive recommendations on the optimal timing of surgery and the role for nonoperative management. This review addresses the best available evidence regarding treatment modality and timing, with an emphasis on creating a management algorithm to identify those patients who can safely be spared surgery.

\section{Search Methods}

A National Library of Medicine (PubMed) computerized literature search of studies published between January 1950 and May 2014 was undertaken using the Medical Subject Heading "epidural abscess spinal." This search acquired 1325 citations for review after excluding non-English-language references. The titles and abstracts of these publications were reviewed. Literature analysis was focused on identifying original clinical articles reporting treatment and outcome in human patients with SEA. Relevant articles were critically reviewed and additional citations were extracted from their reference lists. This resulted in 28 original clinical articles containing at least 30 study subjects from which the majority of the data for this review were obtained. ${ }^{1,3,4}$, $6,11-14,16,18-20,28,31,32,34,36,37,47,48,54,56,59,61,62,65,69,72$ The study design and conclusions of the 10 largest cohorts, each containing more than 50 cases, are summarized in Table 1 . The appropriateness of conclusions drawn from these studies was approximated by ranking the level of evidence. Class I evidence is generated from well-designed randomized controlled clinical trials. Class II evidence comes from well-designed comparative clinical studies and less-welldesigned randomized controlled trials. All of the conclusions for the surgical treatment of SEA for this review were from case series, comparative studies with historical controls, case reports, expert opinion, and flawed prospective studies, representing Class III evidence..$^{10,52,67}$

\section{Operative Versus Nonoperative Management}

Early large reviews and expert opinion strongly favored emergency surgical evacuation in all patients with SEA to prevent progressive neurological deficit. ${ }^{4,14,16,17,27,28}$ Modern treatment algorithms for spinal infection continue to list evidence of epidural abscess as an indication for operative management. ${ }^{21}$ With heightened disease awareness, improved antibiotics, and better availability of imaging studies such as MRI, patients are more often being diagnosed with SEA early in the disease process. ${ }^{19}$ This has led some groups to publish large case series reporting similar outcomes with initial operative and nonoperative strategies in highly selected patient populations. . $^{1,11,37,48,54,56,62}$ In these retrospective case series, nonoperative candidates are chosen based on the clinical judgment of the treating surgeon and include a high proportion of patients whose SEA is identified prior to the development of neurological deficit. Better defining the significant factors that allow for safe triage to medical management is therefore a high priority. There is relative consensus in the published literature that patients with acute or progressive neurological deficit, spi- 
The operative management of spinal epidural abscess

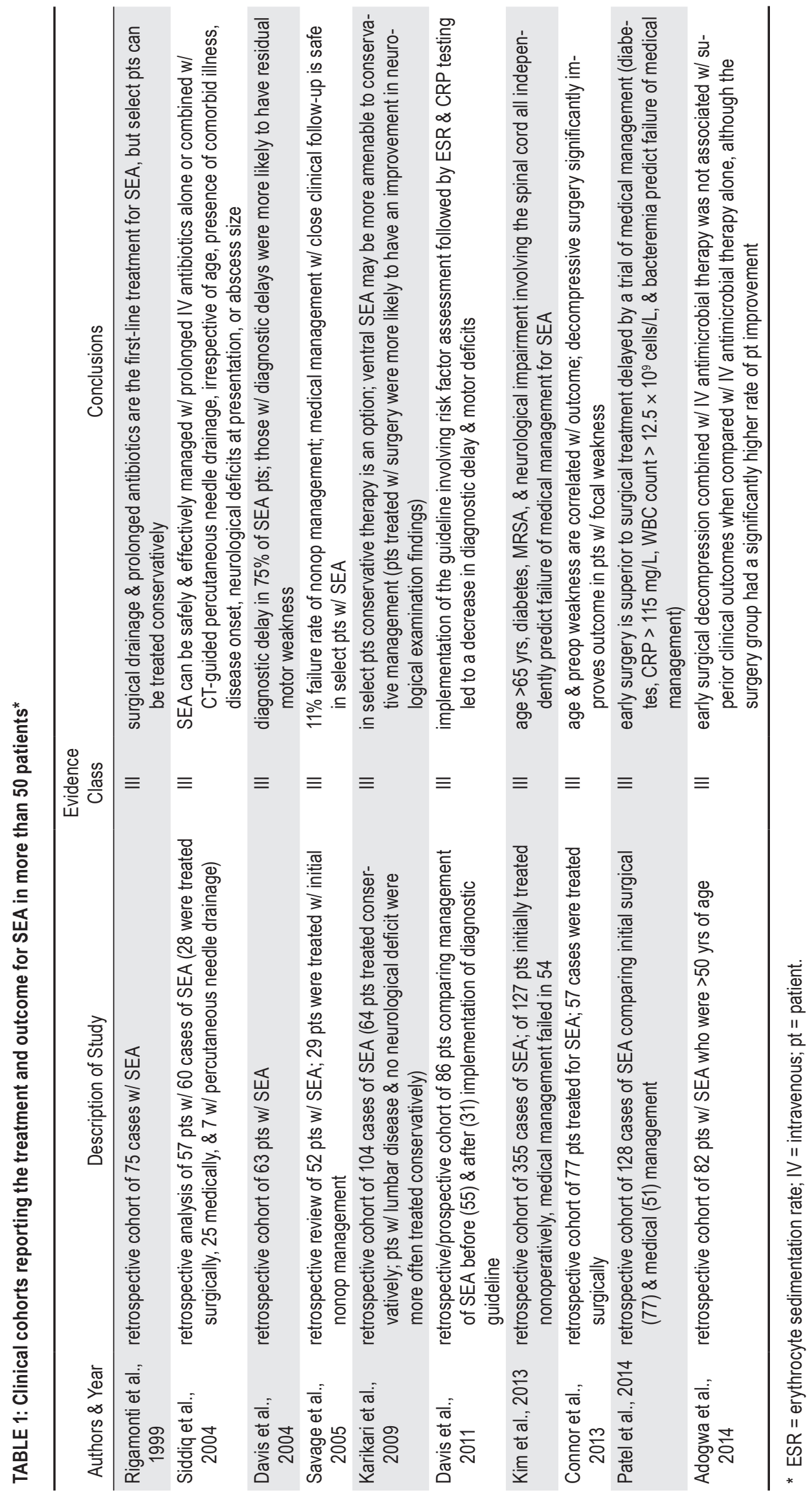




\section{A. Tuchman, M. Pham, and P. C. Hsieh}

nal instability, progressive deformity, or disease progression despite antibiotics require surgical intervention..$^{17,29,50}$ A variety of recent publications have attempted to find other factors that predict a failure of medical management. Keep in mind that all of the current published series are retrospective and are thereby subject to significant selection biases skewing the cohorts treated with antibiotics alone toward smaller abscess size and better initial neurological function. . $^{14,56,59,61}$

Connor et al. ${ }^{13}$ reported their experience in treating 77 patients with SEA, of whom 57 were managed operatively. They found that age and preoperative weakness are correlated with worse outcome. Overall they found no statistically significant difference between patients treated with surgery and antibiotics versus antibiotics alone, which they attribute to probable allocation bias. Decompressive surgery did significantly improve outcome in patients presenting with a motor deficit. Uchida et al. ${ }^{65}$ described MRI characteristics of SEA and reported that no cases with a "ring-like" enhancement pattern were successfully managed nonoperatively.

Patel et al. ${ }^{48}$ highlighted the importance of careful patient selection when deciding to treat SEA with antibiotics alone. In their retrospective review of 128 cases they found that early surgery had better neurological outcomes than delayed surgery after a trial of medical management. Furthermore, they reported a $41 \%$ failure rate, with patients who initially attempted medical management going on to require surgery. They identified 4 parameters that independently predicted failure of medical management: diabetes mellitus; CRP $>115 \mathrm{mg} / \mathrm{L}$; white blood cell (WBC) count $>12.5 \times 10^{9}$ cells $/ \mathrm{L}$; and bacteremia. $\mathrm{Pa}-$ tients without these high-risk features were successfully treated with antibiotics alone $91.7 \%$ of the time.

Kim et al. ${ }^{37}$ reported a detailed analysis of $127 \mathrm{pa}-$ tients initially treated nonoperatively. They reported a failure rate of $43 \%$, defined by delayed surgery or death directly related to unsuccessful medical management. Age older than 65 years, diabetes mellitus, methicillinresistant S. aureus (MRSA) infection, and neurological impairment involving the spinal cord were all found to be independent predictors for failure of medical management. Patients with none of these high-risk features had a $17 \%$ probability that antibiotic management would fail; this increased to at least 33\% if they had 1 high-risk feature, and $99 \%$ if all 4 high-risk features were present.

Adogwa et al. ${ }^{1}$ reported on 82 patients older than 50 years and concluded that early surgical decompression combined with intravenous antimicrobial therapy was clinically equivalent to intravenous antimicrobial therapy alone. They came to this conclusion despite the fact that the surgery group had a significantly higher rate of good neurological outcomes by a factor of more than 2 . They argue that in an older population with more comorbidities the risks of surgical intervention may outweigh the expected neurological benefit from early decompression. This finding should be taken into account when considering the correlation of age older than 65 years with failure of medical management reported by Kim et al., ${ }^{37}$ because increasing age may be associated with worse outcomes for both initial operative and nonoperative management.
Based on the best available evidence, medical management can be a safe and effective treatment strategy for SEA in highly selected patient populations. ${ }^{1,2,7,11,22,37,40,48,54 \text {, }}$ ${ }_{62,68,70}$ Figure 1 summarizes our evidence-based treatment algorithm to safely triage patients to initial operative or nonoperative management. Initial nonoperative management is indicated in patients who are not medically stable for surgery. ${ }^{17,27}$ In cases of complete spinal cord injury for at least 48 hours prior to presentation we also advocate initial nonoperative management, because the surgical risks probably outweigh the chance of functional neurological recovery at that point. ${ }^{17,25,27,54,55,71}$ Obviously surgery may still be indicated if there is concern for an ascending deficit, such as in cases where the clinical level is lower than the anatomical location of the infection.

Furthermore, care must be taken not to improperly classify patients as having sustained complete spinal cord injuries in cases in which there is evidence of spinal shock or barriers to adequate assessment. ${ }^{25}$ Neurologically stable patients lacking reported high-risk features for failure of medical management including diabetes mellitus, ${ }^{37,48}$ MRSA infection, ${ }^{37}$ neurological impairment involving the spinal cord, ${ }^{37}$ acute or progressive motor deficit, ${ }^{13}$ CRP $>115 \mathrm{mg} / \mathrm{L}{ }^{48} \mathrm{WBC}$ count $>12.5 \times 10^{9}$ cells $/ \mathrm{L},{ }^{48}$ ring-like enhancement on MRI ${ }^{65}$ or bacteremia ${ }^{48}$ can be offered nonoperative management with close monitoring as the initial line of treatment. The patient and treating physician must be aware that even in the absence of risk factors there is no guarantee that medical management will not fail and that the patient will not go on to require surgery. In fact, in the two papers that evaluated this circumstance, the risk for failure of medical management remained between $8.3 \%$ and $17 \% .37,48$ This is of significant consequence because the best predictor of postoperative neurological outcome is preoperative neurological

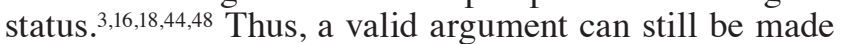
that when feasible, the first-line treatment for SEA should remain urgent surgical decompression before a possible progression in disease causing a decline in neurological examination.

\section{Timing of Surgery}

In 1948 Heusner advocated early surgical evacuation for SEA after reporting no cases of complete neurological recovery in patients with paresis more than 36 hours prior to surgery. ${ }^{27}$ Traditionally, SEA has been treated as a surgical emergency; therefore, few clinical studies are able to comment on the timing of surgery without introducing confounding biases. For example, Connor et al. found no significant association between outcome and time to surgery, with $56 \%$ of patients undergoing operation within 24 hours of presentation. ${ }^{13}$ However, in this study patients with acute loss of motor strength or bowel and/or bladder control generally received emergency surgical decompression. Thus, allocation biases probably played a large role in the nonsignificant outcome for surgical timing because patients with an indolent disease course preferentially received delayed surgery. Also, the broad definitions of outcome used in this study (death, worsened or no improvement, minimal improvement, improved, 


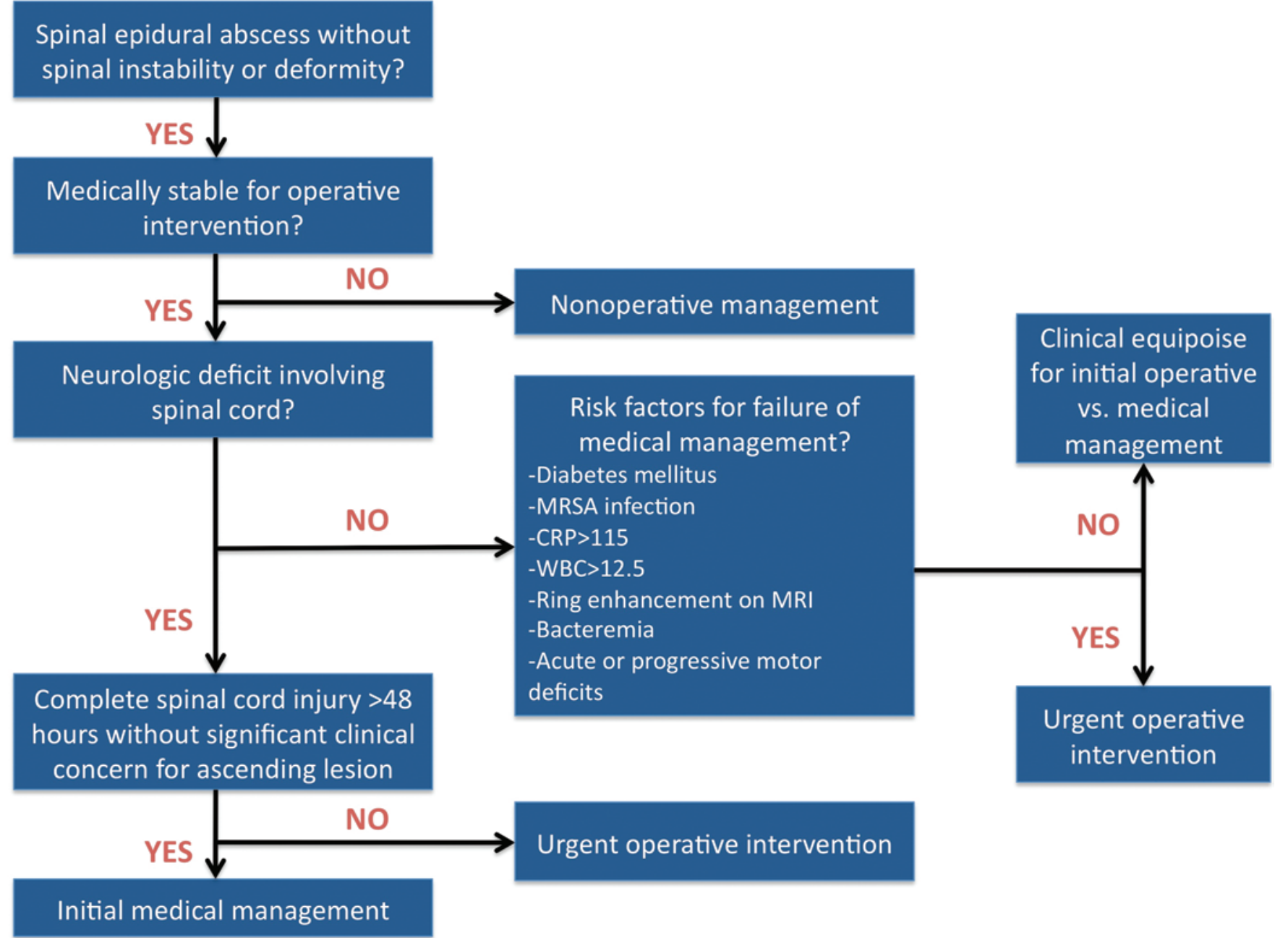

FIG. 1. Evidence-based algorithm for triaging patients with SEA to operative treatment combined with antibiotics versus nonoperative treatment with antibiotics alone. Units of measure used for CRP were $\mathrm{mg} / \mathrm{L}$, and for WBC count the units were $\times 10^{9}$ cells/L.

or resolved) may miss subtle differences in neurological examination results. Patel et al. ${ }^{48}$ used American Spinal Injury Association motor scores to obtain more detailed outcome data. They found that although patients who received urgent versus delayed surgery had no significant difference in final motor outcome, on average the delayed surgery group was weaker compared with the findings at presentation, whereas the immediate surgery group improved. These authors concluded that surgical intervention should be initiated as soon after diagnosis as possible because the ability to recover motor function after failed medical management is significantly impaired.

The finding by multiple groups that time to diagnosis significantly affects neurological outcome supports the idea that when it comes to treating suspected SEA, earlier is better. ${ }^{16,19,20}$ Although most patients with SEA generally progress through back pain, root pain, weakness, and paralysis sequentially, the rate of this progression is highly variable. ${ }^{16,18,27,36}$ Some patients remain with back pain for more than a month, whereas others will go from mild symptomatology to complete paralysis within a few hours. ${ }^{4,16,18,60}$ Multiple series have confirmed that waiting to treat SEA until after a neurological deficit has been sustained leads to worse outcomes. ${ }^{13,17,48}$ Due to the rarity of the disease process and ethical concerns, a welldesigned study directly comparing time to surgery and outcome is unlikely to be designed. Thus, we are left to decide the timing of surgery for each patient based on estimations of the expected disease course and the consequences of delayed treatment. We thereby recommend emergency surgical evacuation for SEA once the decision is made to proceed with operative management.

Multiple large series have noted that if symptoms of SEA have progressed to complete paralysis for more than 24-48 hours, the likelihood of recovery is exceedingly small. ${ }^{16,18,27,54,71}$ Postoperative morbidity following treatment of SEA has been reported to be as high as $38 \%$ (Connor et al.). Thus, many authors have recommended that in patients with long-standing spinal cord injuries, surgery should be reserved for stabilization, failure of medical management to control infection, or debridement, because the rare possibility of functional recovery 
is outweighed by the risks of surgical intervention. ${ }^{17}$ The pathophysiological mechanisms by which infection injures the spinal cord are probably distinct from traumatic spinal cord injury. Unlike trauma, in SEA there may be a window in which complete spinal cord injuries still have a reasonable chance to recover. ${ }^{25,38}$ There are multiple reports of patients who present with acute (less than 48 hours) complete loss of neurological function secondary to SEA who go on to have a good recovery with emergency surgery. ${ }^{38,43,64}$ The exact time point at which a neurological deficit from SEA becomes permanent despite maximal treatment cannot be inferred from the current body of literature. We therefore continue to recommend emergency surgical debridement if onset of complete spinal cord injury is less than 48 hours.

\section{Conclusions}

Despite advances in its medical and surgical treatment, SEA remains a morbid disease process. Patients who are unable to undergo an operation, have complete spinal cord injury for longer than 48 hours with a low risk for rapid ascension of neurological level, or who are neurologically intact and lack clinical and radiographic risk factors for failure of medical management may be treated with antibiotics alone and close clinical monitoring. If initial medical management is to be undertaken, the patient should be made aware that delayed neurological deterioration may not fully recover even after prompt surgical treatment. Patients who are deemed good surgical candidates should receive their operation as soon as possible because the rate of clinical deterioration with SEA is notoriously unpredictable. Although patients tend to recover from acute neurological deficits after treatment of SEA, the time point when a neurological injury becomes irreversible is unknown, further supporting emergency surgery in those patients with acute neurological findings.

\section{Disclosure}

The authors report no conflict of interest concerning the materials or methods used in this study or the findings specified in this paper.

Author contributions to the study and manuscript preparation include the following. Conception and design: all authors. Acquisition of data: Tuchman. Analysis and interpretation of data: all authors. Drafting the article: Tuchman, Pham. Critically revising the article: Tuchman, Hsieh. Reviewed submitted version of manuscript: all authors. Approved the final version of the manuscript on behalf of all authors: Tuchman. Administrative/technical/material support: Tuchman, Pham. Study supervision: Hsieh.

\section{References}

1. Adogwa O, Karikari IO, Carr KR, Krucoff M, Ajay D, Fatemi $\mathrm{P}$, et al: Spontaneous spinal epidural abscess in patients 50 years of age and older: a 15-year institutional perspective and review of the literature. Clinical article. J Neurosurg Spine 20:344-349, 2014

2. Ahl T, Hedström M, von Heijne A, Hammers Stiernstedt S: Acute spinal epidural abscess without concurrent spondylodiscitis. Successful closed treatment in 10 cases. Acta Orthop Scand 70:199-202, 1999

3. Akalan N, Ozgen T: Infection as a cause of spinal cord com- pression: a review of 36 spinal epidural abscess cases. Acta Neurochir (Wien) 142:17-23, 2000

4. Baker AS, Ojemann RG, Swartz MN, Richardson EP Jr: Spinal epidural abscess. N Engl J Med 293:463-468, 1975

5. Bluman EM, Palumbo MA, Lucas PR: Spinal epidural abscess in adults. J Am Acad Orthop Surg 12:155-163, 2004

6. Boström A, Oertel M, Ryang Y, Rohde V, Bürgel U, Krings T, et al: Treatment strategies and outcome in patients with nontuberculous spinal epidural abscess-a review of 46 cases. Minim Invasive Neurosurg 51:36-42, 2008

7. Bouchez B, Arnott G, Delfosse JM: Acute spinal epidural abscess. J Neurol 231:343-344, 1985

8. Browder J, Meyers R: Pyogenic infections of the spinal epidural space. Surgery 10:296-308, 1941

9. Browder R, Meyers R: Infection of the spinal epidural space: an aspect of vertebral osteomyelitis. Am J Surg 37:4-26, 1937

10. Bullock MR, Povlishock JT: Guidelines for the management of severe traumatic brain injury. Editor's Commentary. J Neurotrauma 24 Suppl 1:vii-viii, 2007 (Erratum in J Neurotrauma $25: 276-278,2008$ )

11. Chen SH, Chang WN, Lu CH, Chuang YC, Lui CC, Chen SF, et al: The clinical characteristics, therapeutic outcome, and prognostic factors of non-tuberculous bacterial spinal epidural abscess in adults: a hospital-based study. Acta Neurol Taiwan 20:107-113, 2011

12. Chen WC, Wang JL, Wang JT, Chen YC, Chang SC: Spinal epidural abscess due to Staphylococcus aureus: clinical manifestations and outcomes. J Microbiol Immunol Infect 41: 215-221, 2008

13. Connor DE Jr, Chittiboina P, Caldito G, Nanda A: Comparison of operative and nonoperative management of spinal epidural abscess: a retrospective review of clinical and laboratory predictors of neurological outcome. Clinical article. J Neurosurg Spine 19:119-127, 2013

14. Curry WT Jr, Hoh BL, Amin-Hanjani S, Eskandar EN: Spinal epidural abscess: clinical presentation, management, and outcome. Surg Neurol 63:364-371, 2005

15. Cwikiel W: Percutaneous drainage of abscess in psoas compartment and epidural space. Case report and review of the literature. Acta Radiol 32:159-161, 1991

16. Danner RL, Hartman BJ: Update on spinal epidural abscess: 35 cases and review of the literature. Rev Infect Dis 9:265274, 1987

17. Darouiche RO: Spinal epidural abscess. N Engl J Med 355: 2012-2020, 2006

18. Darouiche RO, Hamill RJ, Greenberg SB, Weathers SW, Musher DM: Bacterial spinal epidural abscess. Review of 43 cases and literature survey. Medicine (Baltimore) 71:369385, 1992

19. Davis DP, Salazar A, Chan TC, Vilke GM: Prospective evaluation of a clinical decision guideline to diagnose spinal epidural abscess in patients who present to the emergency department with spine pain. Clinical article. J Neurosurg Spine 14:765-770, 2011

20. Davis DP, Wold RM, Patel RJ, Tran AJ, Tokhi RN, Chan TC, et al: The clinical presentation and impact of diagnostic delays on emergency department patients with spinal epidural abscess. J Emerg Med 26:285-291, 2004

21. Duarte RM, Vaccaro AR: Spinal infection: state of the art and management algorithm. Eur Spine J 22:2787-2799, 2013

22. Duc C, Grange L, Gaudin P, Brun F, Terki RK, Barbier LP, et al: Extensive primary epidural abscess. Report of a case. Joint Bone Spine 69:312-315, 2002

23. Feldenzer JA, McKeever PE, Schaberg DR, Campbell JA, Hoff JT: Experimental spinal epidural abscess: a pathophysiological model in the rabbit. Neurosurgery 20:859-867, 1987

24. Feldenzer JA, McKeever PE, Schaberg DR, Campbell JA, Hoff JT: The pathogenesis of spinal epidural abscess: micro- 
angiographic studies in an experimental model. J Neurosurg 69:110-114, 1988

25. Fisher CG, Noonan VK, Smith DE, Wing PC, Dvorak MF, Kwon BK: Motor recovery, functional status, and health-related quality of life in patients with complete spinal cord injuries. Spine (Phila Pa 1976) 30:2200-2207, 2005 [Erratum in Spine (Phila Pa 1976) 31:1289, 2006]

26. Friedly J, Standaert C, Chan L: Epidemiology of spine care: the back pain dilemma. Phys Med Rehabil Clin N Am 21: 659-677, 2010

27. Heusner AP: Nontuberculous spinal epidural infections. N Engl J Med 239:845-854, 1948

28. Hlavin ML, Kaminski HJ, Ross JS, Ganz E: Spinal epidural abscess: a ten-year perspective. Neurosurgery 27:177-184, 1990

29. Hsieh PC, Wienecke RJ, O'Shaughnessy BA, Koski TR, Ondra SL: Surgical strategies for vertebral osteomyelitis and epidural abscess. Neurosurg Focus 17(6):E4, 2004

30. Iwasaki M, Yano S, Aoyama T, Hida K, Iwasaki Y: Acute onset intramedullary spinal cord abscess with spinal artery occlusion: a case report and review. Eur Spine J 20 (Suppl 2): S294-S301, 2011

31. Joshi SM, Hatfield RH, Martin J, Taylor W: Spinal epidural abscess: a diagnostic challenge. Br J Neurosurg 17:160-163, 2003

32. Karikari IO, Powers CJ, Reynolds RM, Mehta AI, Isaacs RE: Management of a spontaneous spinal epidural abscess: a single-center 10-year experience. Neurosurgery 65:919-924, 2009

33. Kaufman DM, Kaplan JG, Litman N: Infectious agents in spinal epidural abscesses. Neurology 30:844-850, 1980

34. Kempthorne JT, Pratt C, Smale EL, MacFarlane MR: Tenyear review of extradural spinal abscesses in a New Zealand tertiary referral centre. J Clin Neurosci 16:1038-1042, 2009

35. Khan SH, Hussain MS, Griebel RW, Hattingh S: Title comparison of primary and secondary spinal epidural abscesses: a retrospective analysis of 29 cases. Surg Neurol 59:28-33, 2003

36. Khanna RK, Malik GM, Rock JP, Rosenblum ML: Spinal epidural abscess: evaluation of factors influencing outcome. Neurosurgery 39:958-964, 1996

37. Kim SD, Melikian R, Ju KL, Zurakowski D, Wood KB, Bono $\mathrm{CM}$, et al: Independent predictors of failure of nonoperative management of spinal epidural abscesses. Spine J [epub ahead of print], 2013

38. Koo DW, Townson AF, Dvorak MF, Fisher CG: Spinal epidural abscess: a 5-year case-controlled review of neurologic outcomes after rehabilitation. Arch Phys Med Rehabil 90: 512-516, 2009

39. Lange M, Tiecks F, Schielke E, Yousry T, Haberl R, Oeckler R: Diagnosis and results of different treatment regimens in patients with spinal abscesses. Acta Neurochir (Wien) 125:105-114, 1993

40. Leys D, Lesoin F, Viaud C, Pasquier F, Rousseaux M, Jomin $\mathrm{M}$, et al: Decreased morbidity from acute bacterial spinal epidural abscesses using computed tomography and nonsurgical treatment in selected patients. Ann Neurol 17:350-355, 1985

41. Liem LK, Rigamonti D, Wolf AL, Robinson WL, Edwards CC, DiPatri A: Thoracic epidural abscess. J Spinal Disord 7:449-454, 1994

42. Löhr M, Reithmeier T, Ernestus RI, Ebel H, Klug N: Spinal epidural abscess: prognostic factors and comparison of different surgical treatment strategies. Acta Neurochir (Wien) 147:159-166, 2005

43. Mann S, Schütze M, Sola S, Piek J: Nonspecific pyogenic spondylodiscitis: clinical manifestations, surgical treatment, and outcome in 24 patients. Neurosurg Focus 17(6):E3, 2004

44. McGee-Collett M, Johnston IH: Spinal epidural abscess: presentation and treatment. A report of 21 cases. Med J Aust 155:14-17, 1991
45. Mixter WJ, Smithwick RH: Acute intraspinal epidural abscess. N Engl J Med 207:126-131, 1932

46. Morgagni JB: The Seats and Causes of Diseases Investigated by Anatomy; in Five Books, Containing a Great Variety of Dissections, With Remarks. To Which Are Added Very Accurate and Copious Indexes of the Principal Things and Names Therein Contained. Alexander B, trans. London: Johnson and Payne, 1769

47. Nussbaum ES, Rigamonti D, Standiford H, Numaguchi Y, Wolf AL, Robinson WL: Spinal epidural abscess: a report of 40 cases and review. Surg Neurol 38:225-231, 1992

48. Patel AR, Alton TB, Bransford RJ, Lee MJ, Bellabarba CB, Chapman JR: Spinal epidural abscesses: risk factors, medical versus surgical management, a retrospective review of 128 cases. Spine J 14:326-330, 2014

49. Payer M, Walser H: Evacuation of a 14-vertebral-level cervico-thoracic epidural abscess and review of surgical options for extensive spinal epidural abscesses. J Clin Neurosci 15:483-486, 2008

50. Pradilla G, Ardila GP, Hsu W, Rigamonti D: Epidural abscesses of the CNS. Lancet Neurol 8:292-300, 2009

51. Reihsaus E, Waldbaur H, Seeling W: Spinal epidural abscess: a meta-analysis of 915 patients. Neurosurg Rev 23:175-205, 2000

52. Resnick DK, Choudhri TF, Dailey AT, Groff MW, Khoo L, Matz PG, et al: Guidelines for the performance of fusion procedures for degenerative disease of the lumbar spine. Part 1: introduction and methodology. J Neurosurg Spine 2:637638,2005

53. Reynolds F: Neurological infections after neuraxial anesthesia. Anesthesiol Clin 26:23-52, v, 2008

54. Rigamonti D, Liem L, Sampath P, Knoller N, Namaguchi Y, Schreibman DL, et al: Spinal epidural abscess: contemporary trends in etiology, evaluation, and management. Surg Neurol 52:189-197, 1999

55. Russell NA, Vaughan R, Morley TP: Spinal epidural infection. Can J Neurol Sci 6:325-328, 1979

56. Savage K, Holtom PD, Zalavras CG: Spinal epidural abscess: early clinical outcome in patients treated medically. Clin Orthop Relat Res 439:56-60, 2005

57. Sendi P, Bregenzer T, Zimmerli W: Spinal epidural abscess in clinical practice. QJM 101:1-12, 2008

58. Shah NH, Roos KL: Spinal epidural abscess and paralytic mechanisms. Curr Opin Neurol 26:314-317, 2013

59. Siddiq F, Chowfin A, Tight R, Sahmoun AE, Smego RA Jr: Medical vs surgical management of spinal epidural abscess. Arch Intern Med 164:2409-2412, 2004

60. Simpson RK Jr, Azordegan PA, Sirbasku DM, Weathers SW, Lidsky MD, Baskin DS: Rapid onset of quadriplegia from a panspinal epidural abscess. Spine (Phila Pa 1976) 16:10021005,1991

61. Sørensen P: Spinal epidural abscesses: conservative treatment for selected subgroups of patients. Br J Neurosurg 17:513518,2003

62. Tang HJ, Lin HJ, Liu YC, Li CM: Spinal epidural abscessexperience with 46 patients and evaluation of prognostic factors. J Infect 45:76-81, 2002

63. Tompkins M, Panuncialman I, Lucas P, Palumbo M: Spinal epidural abscess. J Emerg Med 39:384-390, 2010

64. Turgut M: Complete recovery of acute paraplegia due to pyogenic thoracic spondylodiscitis with an epidural abscess. Acta Neurochir (Wien) 150:381-386, 2008

65. Uchida K, Nakajima H, Yayama T, Sato R, Kobayashi S, Chen $\mathrm{KB}$, et al: Epidural abscess associated with pyogenic spondylodiscitis of the lumbar spine; evaluation of a new MRI staging classification and imaging findings as indicators of surgical management: a retrospective study of 37 patients. Arch Orthop Trauma Surg 130:111-118, 2010

66. van de Warrenburg BP, Wesseling P, Leyten QH, Boerman 


\section{A. Tuchman, M. Pham, and P. C. Hsieh}

RH: Myelopathy due to spinal epidural abscess without cord compression: a diagnostic pitfall. Clin Neuropathol 23:102106,2004

67. Walters BC: Methodology of the guidelines for the management of acute cervical spine and spinal cord injuries. Neurosurgery 72 (Suppl 2): 17-21, 2013

68. Wheeler D, Keiser P, Rigamonti D, Keay S: Medical management of spinal epidural abscesses: case report and review. Clin Infect Dis 15:22-27, 1992

69. Wu MY, Fu TS, Chang CH, Hsu HH, Chang MY, Tian YC, et al: Aggressive surgical intervention in end-stage renal disease patients with spinal epidural abscess. Ren Fail 33:582-586, 2011

70. Xiao BR, Wang CW, Lin JC, Chang FY: Successful medical treatment of spinal epidural abscess. J Microbiol Immunol Infect 41:180-182, 2008
71. Yang SY: Spinal epidural abscess. N Z Med J 95:302-304, 1982

72. Zimmerer SM, Conen A, Müller AA, Sailer M, Taub E, Flückiger U, et al: Spinal epidural abscess: aetiology, predisponent factors and clinical outcomes in a 4-year prospective study. Eur Spine J 20:2228-2234, 2011

Manuscript submitted May 24, 2014.

Accepted June 11, 2014.

Please include this information when citing this paper: DOI: 10.3171/2014.6.FOCUS14261.

Address correspondence to: Alexander Tuchman, M.D., Department of Neurosurgery, University of Southern California, 1200 N. State St., Ste. 3300, Los Angeles, CA 90089. email: alexandertuch man@gmail.com. 